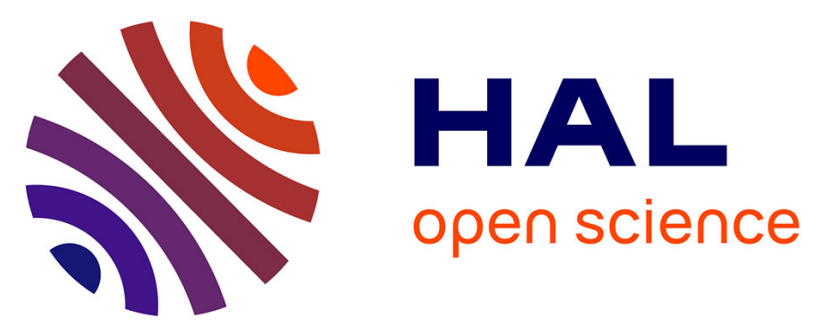

\title{
Stronger association of drug-induced progressive multifocal leukoencephalopathy (PML) with biological immunomodulating agents
}

Carlo Piccinni, Chiara Sacripanti, Elisabetta Poluzzi, Domenico Motola, Lara Magro, Ugo Moretti, Anita Conforti, Nicola Montanaro

\section{To cite this version:}

Carlo Piccinni, Chiara Sacripanti, Elisabetta Poluzzi, Domenico Motola, Lara Magro, et al.. Stronger association of drug-induced progressive multifocal leukoencephalopathy (PML) with biological immunomodulating agents. European Journal of Clinical Pharmacology, 2009, 66 (2), pp.199-206. $10.1007 / \mathrm{s} 00228-009-0739-\mathrm{z}$. hal-00535000

\section{HAL Id: hal-00535000 https://hal.science/hal-00535000}

Submitted on 11 Nov 2010

HAL is a multi-disciplinary open access archive for the deposit and dissemination of scientific research documents, whether they are published or not. The documents may come from teaching and research institutions in France or abroad, or from public or private research centers.
L'archive ouverte pluridisciplinaire HAL, est destinée au dépôt et à la diffusion de documents scientifiques de niveau recherche, publiés ou non, émanant des établissements d'enseignement et de recherche français ou étrangers, des laboratoires publics ou privés. 


\title{
Stronger association of drug-induced progressive multifocal leukoencephalopathy (PML) with biological immunomodulating agents
}

\author{
Carlo Piccinni • Chiara Sacripanti • Elisabetta Poluzzi • \\ Domenico Motola • Lara Magro • Ugo Moretti • \\ Anita Conforti • Nicola Montanaro
}

Received: 26 May 2009 / Accepted: 23 September 2009 /Published online: 17 October 2009

(C) Springer-Verlag 2009

\begin{abstract} or drug immunosuppression in PML occurrence. drugs. therapeutic groups, concomitant drugs were reported.

\footnotetext{
C. Piccinni $\cdot$ C. Sacripanti $\cdot$ E. Poluzzi $\cdot$ D. Motola $\cdot$

N. Montanaro $(\square)$

Department of Pharmacology, University of Bologna,

Via Irnerio, 48 ,

40126 Bologna, Italy

e-mail: nicola.montanaro@unibo.it

L. Magro $\cdot$ U. Moretti $\cdot$ A. Conforti

Clinical Pharmacology Unit, University of Verona,

P.le Ludovico Antonio Scuro, 10,
}

37134 Verona, Italy
\end{abstract}

Aim The aim of the present study was to collect and compare cases of drug-induced PML in order to contribute to the debate about the role of the underlying diseases and/

Methods We searched for drug-induced PML cases in two international spontaneous adverse drug reaction (ADR) report databases, FDA-AERS and WHO-VigiBase. From MEDLINE, we retrieved case reports and case series containing the MESH term "leukoencephalopathy, progressive multifocal/chemically induced". In order to assess the PML-drug relationship, we analysed drug-reaction pairs in terms of the patients' underlying diseases and co-suspected

Results Overall, 214 cases in FDA-AERS, 118 in WHOVigiBase and 140 in MEDLINE were collected. Therapeutic groups more frequently involved in PML cases were monoclonal antibodies (MAbs), conventional immunosuppressive drugs and anti-HIV drugs. The most frequent underlying diseases were lymphoproliferative diseases (28\%), autoimmune disorders $(20 \%)$ and transplants $(10 \%)$. MAbs were more often reported in cases where they were the only suspected drugs, whereas for the other
Conclusions We found a strong relationship between PML and MAbs, especially when used in autoimmune diseases. PML is becoming a crucial issue of MAbs, since they can cause severe ADRs through the imbalance of the immune system. Based on these results, patients treated with MAbs should be carefully monitored for early signs and symptoms of PML.

Keywords Progressive multifocal leukoencephalopathy · Adverse drug reaction · Reporting system · Database · Monoclonal antibody

\section{Introduction}

Progressive multifocal leukoencephalopathy (PML) is a demyelinating disease affecting the central nervous system that is associated with a high rate of mortality. It is caused by a reactivation of the polyomavirus $\mathrm{JC}$, which induces a lytic infection of the oligodendrocytes [1]. There are a number of unsolved issues related to pathogenetic mechanisms and diagnostic procedures of the disease; moreover there is no current specific treatment for JC virus. The importance of PML in global health has considerably increased over the past 50 years. Until the 1970s, it was considered a scarcely known condition affecting only patients with haematopathies and organ transplant recipients, whereas afterwards PML evolved as a major complication of HIV [2], bringing to the hypothesis that immune-deficient states, either disease- or drug-related, were predisposing factors for PML.

The interest in PML increased when natalizumab, a new immunomodulating agent for multiple sclerosis, was withdrawn from the U.S. market (February 2005) only 4 months 
after its authorization (November 2004) because of three cases of PML in patients receiving a combination of immunomodulating or immunosuppressive drugs [3-5]. Afterward, on the basis of observational studies [6] and a post-hoc analysis of the AFFIRM trial [7], natalizumab was resumed in the U.S. and was approved in Europe as a monotherapy and under a close monitoring programme and restrictions. However, in 2008 at least three new PML cases in patients treated with natalizumab as monotherapy appeared among the European population.

Because of a few other cases among patients with immune-mediated disease treated with different immunomodulating agents, including rituximab, efalizumab and mycophenolic acid [8], PML occurrence was designated as an important safety issue by the main regulatory agencies, and the EMEA established a scientific advisory group on this issue. One of the main questions is whether PML could be a class effect of new immunosuppressive drugs.

Considering the rarity of PML, a post-marketing analysis based on various sources could be useful to better define the drug-reaction relationship.

\begin{abstract}
Aim
The aim of this study was to collect and compare cases of drug-induced PML as reported in the main international spontaneous adverse drug reaction (ADR) databases and in the literature in order to identify active substances associated with this adverse reaction. Elements to establish the role of underlying diseases and the role of general
\end{abstract}

immunosuppression by drugs in the occurrence of PML will be also provided.

\section{Methods}

We searched for cases of drug-induced PML in two spontaneous ADR report databases (US FDA-AERS and WHO-VigiBase). For each retrieved case, event date, data on patient age and gender, therapeutic indication, drug(s) suspected by the reporter and reporter country were collected (see Box 1 for the main characteristics of each source of data and for details on the relevant case selection). Duplicate records were detected within each source and removed before the analysis. They were identified by combining the principal items concerning each case, such as age, gender, event date and reporter country. No pooling was made of records coming from the two ADR databases (FDA and WHO) since possible duplicates of the same ADRs could be present.

To assess the PML-drug relationship, we analysed drugreaction pairs in terms of patient characteristics, underlying diseases and co-suspected drugs.

Drugs were divided into four main groups: (1) monoclonal antibodies (MAbs), (2) anti-HIV drugs, (3) conventional immunosuppressive drugs and (4) others (including antineoplastics, anti-infectives other than anti-HIV and all drugs belonging to therapeutic classes scarcely represented).

In order to provide additional elements in the evaluation of the relationship between therapeutic group and ADR, we classified cases as "single", when only one drug was

Box 1 Characteristics of the two studied ADR databases, US FDA-AERS and WHO-VigiBase

\section{US FDA-AERS}

The US FDA Adverse Event Reporting System (AERS) is a computerised information database designed to support the FDA's post-marketing safety surveillance programme for all approved drug and therapeutic biological products [9]. It contains reports of suspected ADR submitted worldwide in accordance with mandatory reporting obligations by pharmaceutical companies and voluntarily by health-care professionals and consumers. Suspected ADR reports are reviewed and coded for data entry in accordance with the standardised terminology of the Medical Dictionary for Regulatory Activities (MedDRA) [10].

Quarterly data files freely available in October 2008 (including reports from January 2004 and June 2008) were downloaded from the FDA web site. Tables including drug information (DRUG file), adverse events (REACTION file), patient demographic information (DEMO file) and drug indication (INDI file) were considered. All the information from the different tables was linked by a unique number (ISR) for identifying an ADR. All reports of progressive multifocal leukoencephalopathy were selected and primary suspect drugs (PS) and secondary suspect drugs (SS) were identified. Information on patient age and gender, event date, indication for use and reporter country were also collected.

\section{WHO-VigiBase}

The WHO Adverse Drug Reaction Database (VigiBase) holds spontaneously reported cases of suspected ADRs forwarded from 82 national ADR monitoring centres around the world to the WHO Collaborating Centre for International Drug Monitoring, Uppsala Monitoring Centre (UMC) [11]. The case reports are anonymous and heterogeneous and differ as regards source, documentation and relationship-likelihood.

In October 2008, we consulted WHO-VigiBase to find all reported cases of PML by searching within ATC (Anatomical Therapeutic Chemical classification [12]) 4th-level groups using the preferred MedDRA term "progressive multifocal leukoencephalopathy". We collected all case reports for each ATC group. For each case, we extracted data about reporter country, patient gender and age, and suspected drugs with relevant therapeutic indication.

At the time of data collection (October 2008), WHO-VigiBase included more than 4 million case reports, and every quarter 100,000 new reports are added. 
reported as PML-suspected, or "multiple", when two or more drugs were co-suspected. Chi-square test was used to evaluate the difference between the proportions of single and multiple cases in each therapeutic group.

In order to also take into account information published in the literature, we retrieved case reports and case series of PML present in MEDLINE. For this purpose, in October 2008 the MEDLINE database was searched using the MESH term "leukoencephalopathy, progressive multifocal/chemically induced" (index date 1973). We excluded cases associated with substances other than drugs. In order to allow comparisons with results from the spontaneous ADR databases, cases found in the literature were grouped by publication date as (1) before 2004 or (2) from 2004 to October 2008.

\section{Results}

Information from the different sources

Overall, 214 cases (corresponding to 436 drug-reaction pairs) and 118 cases (251 drug-reaction pairs) were collected from FDA-AERS and WHO-VigiBase respectively.

As for MEDLINE, we selected 105 case reports or case series, for a total number of 140 cases (including 111 cases published before 2004 and 29 during the 2004-2008 period). Overall, we collected 169 drug-reaction pairs before 2004 and 53 from 2004-2008.

North America represented the most frequent reporting area of PML cases both for FDA-AERS (55\% of those where the country was reported) and for WHO-VigiBase (76\%), whereas MEDLINE records came more frequently from Europe (22\%) before 2004 and from Asia (34\%) during the 2004-2008 period. A high rate of records missing geographic information was found in all sources (from 14\% in MEDLINE 2004-2008 to 49\% in FDA-AERS).

Analysis of drug-reaction pairs

One hundred and twenty different active substances were identified. Therapeutic groups more involved in PML cases were anti-HIV drugs and conventional immunosuppressive drugs in all the considered sources (Fig. 1), whereas MAbs were more frequently reported in spontaneous ADR databases and in more recent literature. Table 1 shows drugs with $\geq 5$ PML cases in at least one source. From the MAbs group, rituximab and natalizumab (in all sources) and alemtuzumab (in spontaneous ADR databases) were reported. Of the anti-HIV drugs, lamivudine, ritonavir and its combination with lopinavir, zidovudine and stavudine were more often reported in both spontaneous ADR databases. Cyclophosphamide, tacrolimus and prednisone were the most conventional immunosuppressive drugs represented in FDA-AERS and WHO-VigiBase; methotrexate was the only drug with a large number of cases in the older literature. Within the "others" group, vincristine and doxorubicin were more often reported in both spontaneous ADR databases, whereas fluorouracil and levamisole (often used in combination) showed a high number of PML cases in the older literature.

\section{Patient characteristics}

The $\mathrm{M} / \mathrm{F}$ ratio among patients with drug-induced PML was about 1 in all sources; also patient average age was similar among spontaneous report databases and literature, ranging from 51 years in WHO-VigiBase to 45 years in MEDLINE before 2004.

When underlying diseases of patients were considered (Table 2), a large number of drug-induced PML cases were found in HIV subjects, in particular in spontaneous report databases: 58 (27\%) in FDA-AERS and $23(19 \%)$ in WHOVigiBase, whereas there were only 3 cases $(10 \%)$ in MEDLINE 2004-2008 and no cases in the older literature. Lymphoproliferative disorders, especially lymphoma and leukaemia, were reported in similar percentages in all sources (about $28 \%$ of overall cases). Cancer cases were reported above all in the older literature (in particular colon cancer), corresponding to $50 \%$ of all PML cases published before 2004, whereas these patients represented less than $8 \%$ elsewhere. Small percentages of transplants $(5-10 \%)$ were present in all sources.

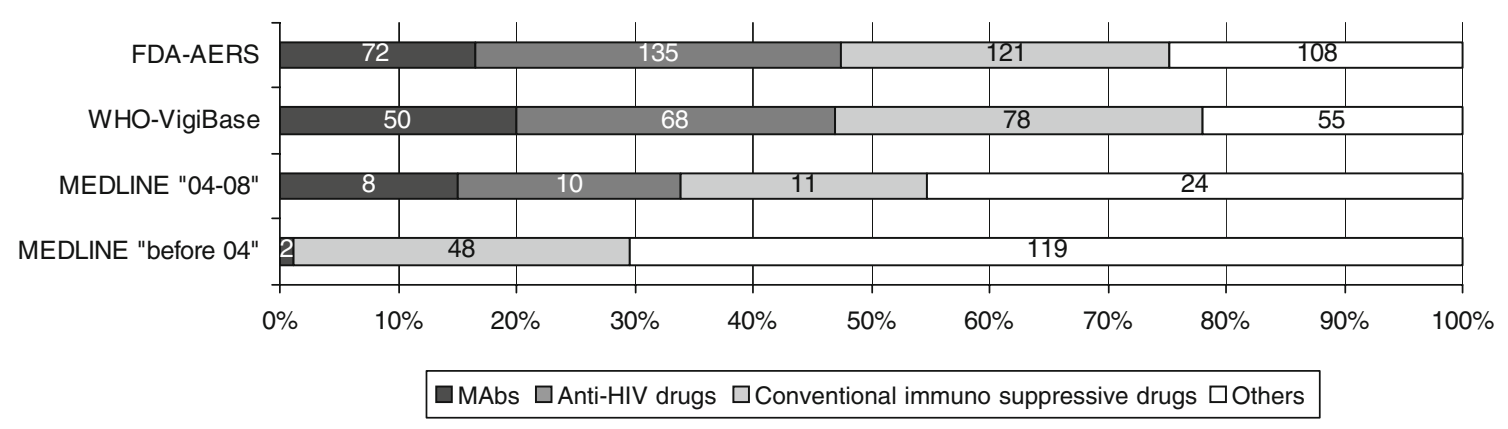

Fig. 1 Therapeutic groups involved in PML cases retrieved from different sources 
Table 1 Drugs with $\geq 5$ PML cases in at least one source

\begin{tabular}{|c|c|c|c|c|c|}
\hline Therapeutic group & Active substances & FDA-AERS & WHO-VigiBase & $\begin{array}{l}\text { MEDLINE, } \\
2004-2008\end{array}$ & $\begin{array}{l}\text { MEDLINE, } \\
\text { before } 2004\end{array}$ \\
\hline \multirow[t]{3}{*}{ MAbs } & Rituximab & 46 & 29 & 5 & 2 \\
\hline & Natalizumab & 13 & 7 & 3 & \\
\hline & Alemtuzumab & 3 & 8 & & \\
\hline \multirow[t]{9}{*}{ Anti-HIV drugs } & Lamivudine & 21 & 11 & 3 & \\
\hline & Lopinavir/ritonavir & 16 & 6 & & \\
\hline & Ritonavir & 14 & 9 & & \\
\hline & Zidovudine & 13 & 6 & 3 & \\
\hline & Stavudine & 12 & 4 & & \\
\hline & Nevirapine & 9 & 5 & 1 & \\
\hline & Efavirenz & 9 & 4 & 2 & \\
\hline & Tenofovir & 6 & 3 & & \\
\hline & Indinavir & 5 & 2 & & \\
\hline \multirow[t]{11}{*}{ Conventional immunosuppressive drugs } & Cyclophosphamide & 23 & 16 & 2 & 2 \\
\hline & Prednisone & 22 & 12 & & \\
\hline & Tacrolimus & 10 & 10 & 2 & 1 \\
\hline & Cyclosporine & 9 & 5 & 1 & 5 \\
\hline & Mycophenolic acid & 8 & 5 & & 1 \\
\hline & Interferon beta-1a & 6 & & & \\
\hline & Azathioprine & 6 & 3 & & 4 \\
\hline & Methotrexate & 6 & 6 & 1 & 29 \\
\hline & Peginterferon alpha- $2 \mathrm{a}$ & 5 & 2 & & \\
\hline & Prednisolone & 5 & 2 & 1 & 2 \\
\hline & Inteferon alpha/beta & & 8 & & \\
\hline \multirow[t]{9}{*}{ Others } & Vincristine & 13 & 6 & 2 & \\
\hline & Doxorubicin & 13 & 7 & 2 & \\
\hline & Fludarabine & 9 & 6 & 1 & 8 \\
\hline & Cytarabine & 9 & 3 & 1 & 7 \\
\hline & Ribavirin & 5 & 1 & & \\
\hline & Fluorouracil & & & 1 & 30 \\
\hline & Carmofur & & & & 6 \\
\hline & Levamisole & & & 7 & 33 \\
\hline & Calcium folinate & & & & 10 \\
\hline
\end{tabular}

About $20 \%$ of all cases were autoimmune disorders (with the exception of older literature, where autoimmune disorders represented only $4 \%$ ). Within these disorders, multiple sclerosis was the most represented with 16 cases in FDAAERS, 10 in WHO-VigiBase and 2 in MEDLINE 20042008. Systemic lupus erythematosus followed, with nine in FDA-AERS, four in WHO-VigiBase, one in MEDLINE 2004-2008 and two in MEDLINE before 2004. Crohn's disease, psoriasis and rheumatoid arthritis were also recorded.

Strength assessment of drug-reaction relationship

Significant differences among therapeutic groups were found concerning the fraction of cases with a single suspected drug [overall chi-square $(\mathrm{df}=3)=47.19$ in FDAAERS $(P<0.0001)$ and 32.72 in WHO-VigiBase $(P<$ $0.0001)$; see Table 3]. This difference was mainly due to MAbs, which were more often reported in cases as single suspected drugs [chi-square $(\mathrm{df}=1)=44.17(P<0.0001)$ and $30.05(P<0.0001)$ respectively]. The remaining therapeutic groups contained agents more often reported as multiple suspected drugs, without significant differences among them.

Concerning the classification into single vs multiple for specific active substances, rituximab (28 vs 18 in FDA-AERS and 20 vs 9 in WHO-VigiBase) and natalizumab ( 9 vs 4 and 4 vs 3 respectively) represented almost the entire the MAbs group. Within the group of conventional immunosuppressive drugs, tacrolimus was the only agent more frequently reported 
Table 2 Underlying diseases classified in pathological macro-areas in patients with drug-induced PML

\begin{tabular}{|c|c|c|c|c|c|c|c|c|}
\hline Disease & $\begin{array}{l}\text { FDA } \\
\text { AERS }(n)\end{array}$ & Percentage & $\begin{array}{l}\text { WHO } \\
\text { VigiBase }(n)\end{array}$ & Percentage & $\begin{array}{l}\text { MEDLINE, } \\
\text { 2004-2008 (n) }\end{array}$ & Percentage & $\begin{array}{l}\text { MEDLINE, } \\
\text { before } 2004(n)\end{array}$ & Percentage \\
\hline HIV & 58 & $27 \%$ & 23 & $19 \%$ & 3 & $10 \%$ & & $0 \%$ \\
\hline $\begin{array}{l}\text { Lymphoproliferative } \\
\text { disorder }\end{array}$ & 55 & $26 \%$ & 39 & $33 \%$ & 8 & $28 \%$ & 31 & $28 \%$ \\
\hline Autoimmune disorder & 46 & $21 \%$ & 22 & $19 \%$ & 6 & $21 \%$ & 4 & $4 \%$ \\
\hline Transplant & 16 & $7 \%$ & 12 & $10 \%$ & 3 & $10 \%$ & 6 & $5 \%$ \\
\hline Cancer & 11 & $5 \%$ & 7 & $6 \%$ & 2 & $7 \%$ & 56 & $50 \%$ \\
\hline $\begin{array}{l}\text { Infections and } \\
\text { infestations }\end{array}$ & 11 & $5 \%$ & 4 & $3 \%$ & & $0 \%$ & 1 & $1 \%$ \\
\hline Others & 10 & $5 \%$ & 2 & $2 \%$ & 7 & $24 \%$ & 8 & $7 \%$ \\
\hline Unknown & 7 & $3 \%$ & 9 & $8 \%$ & & $0 \%$ & 5 & $5 \%$ \\
\hline Total & 214 & $100 \%$ & 118 & $100 \%$ & 29 & $100 \%$ & 111 & $100 \%$ \\
\hline
\end{tabular}

as suspected alone than co-suspected ( 8 vs 2 in FDA-AERS and 7 vs 3 in WHO-VigiBase).

\section{Discussion}

The analysis of spontaneous reports is one of the most useful methods for signal detection of rare ADRs such as PML. FDA-AERS and WHO-VigiBase can be considered the largest sources of these data and the additional analysis of published literature incorporates the main strategies to detect an alert signal on the basis of voluntary reports of ADRs. As argued by Hammond et al., the early safety signal detection should involve the use of multiple large global databases because this permits the use of the largest number of reports for a given drug [13]. This approach is appropriate for a rare ADR, such as PML. Our search of FDA-AERS and WHO-VigiBase identified similar lists of drugs as responsible for PML cases, although the former yielded a higher number of PML records, probably due to both the different methods of data collection and the existence of possible residual duplicate records. The analysis was performed on both spontaneous ADR databases due to their different set-ups and different geograph- ical coverage, although partial overlap among cases in the two databases may exist.

There are a number of limitations on the use of spontaneous ADR databases. The main drawbacks are (1) a lack of details that are useful to the drug-reaction causality assessment, (2) general under-reporting bias, (3) overreporting of drugs involved in safety alerts or regulatory measures (notoriety bias), (4) dependence of the reporting rate on the amount of time the drug was on the market (the Weber effect) and (5) the low quality of data (i.e. missing data, "extreme duplication" and duplicate records) [14-18].

Large differences were found between the spontaneous reports coming from the literature and the two ADR databases, in particular with regard to the number of cases and their distribution among drug classes. For example, anti-HIV drugs were reported almost only in spontaneous ADR databases, probably because of a scarce interest in publishing about the well-known relationship between PML and the immunosuppressive condition of HIV patients [19]. In addition, since anti-HIV treatment consists of multiple drug schedules, it is difficult to establish a clear relationship between a given drug and PML.

With regard to our literature search for PML cases, biases could have derived from a possible lack of
Table 3 Chi-square test for differences between the proportions of cases involving single or multiple drugs in the various therapeutic groups

\begin{tabular}{llllll}
\hline Therapeutic group & \multicolumn{2}{l}{ FDA-AERS } & & \multicolumn{2}{l}{ WHO-VigiBase } \\
\cline { 2 - 3 } & Single & Multiple & & Single & Multiple \\
\hline (A) MAbs & 44 & 28 & & 30 & 20 \\
(B) Anti-HIV drugs & 25 & 110 & & 11 & 57 \\
(C) Conventional immunosuppressive drugs & 29 & 92 & & 17 & 61 \\
(D) Others & 25 & 83 & & 12 & 43 \\
Chi-square, overall (df=3) & $47.19, P<0.0001$ & & $32.72, P<0.0001$ \\
Chi-square, A vs (B+C+D) (df=1) & $44.17, P<0.0001$ & & $30.05, P<0.0001$ \\
Chi-square (B, C, D) (df=2) & $1.30, P=0.52$ & & $0.89, P=0.64$ \\
\hline
\end{tabular}


specificity or sensitivity of the MESH term "leukoencephalopathy, progressive multifocal/chemically induced".

Immunosuppressants were the drugs most represented, and they were divided by us into conventional immunosuppressive drugs and MAbs. A criticism could be the division into these two groups, as it was based on our observed data, but it seemed justified to verify a possible difference between general pharmacological immunosuppression and the impairment of a specific pathway of the immune system. Immunosuppressive drugs obtained in our search were mostly related to patients with lymphoproliferative disorders (e.g. leukaemia) and autoimmune disorders (e.g. multiple sclerosis, psoriasis, rheumatoid arthritis, systemic lupus erythematosus). In the past, PML has never been associated with autoimmune disorders, and it was not considered a listed ADR of conventional immunosuppressive drugs. On the other hand, PML is becoming a crucial issue for new immunosuppressive drugs, especially MAbs. This change could certainly be explained by (1) better PML-diagnostic skills and (2) improved awareness about this matter, but it could also be explained by the fact that (3) PML could be a specific adverse reaction of monoclonal antibodies.

New monoclonal antibodies rituximab and natalizumab have contributed to the recent heated debate on PML [20, 21]. For these agents close safety monitoring systems (e.g. for natalizumab, the TOUCH programme in the U.S.A. [22, 23] and a country-based surveillance programme in Italy [24]) could probably influence reporting of PML cases. The relationship between PML, as well as other opportunistic infections, and monoclonal antibodies is well monitored by regulatory agencies and a patho-physiological plausibility is emerging $[25,26]$ Biological drugs are often wrongly considered safer than non-biological ones because of the lack of off-target effects. However, these new immunosuppressive drugs could cause severe ADRs such as lethal infections or tumours by imbalancing the immune system with high specificity on-target action, as postulated by many authors [27-30]. Hence, this should be acknowledged in assessing safety of biological drugs, also in light of spontaneous reports and published cases. From our results, it is reasonable to wonder if PML can be considered a class effect of immunosuppressive monoclonal antibodies.

To establish the strength of the PML-drug relationship, it is necessary to distinguish when the drug was a single suspected agent of ADR from cases with multiple suspected drugs. Therefore, in our data, monoclonal antibodies, especially rituximab and natalizumab, could be considered more strongly associated with PML. For other therapeutic groups, frequently included in polypharmacy, it is more difficult to establish the causal relationship with PML since it is not possible to identify the main suspected drug. This issue is very important because early PML cases in natalizumab recipients developed in clinical trials where natalizumab was used in association with interferon or immunosuppressive drugs [31, 32]. In order to avoid strong immunosuppression from a drug-drug combination, the use of natalizumab was restricted to monotherapy of relapsing remitting multiple sclerosis. However, the most recent PML cases occurred with natalizumab monotherapy [33]. Similarly, many PML cases were recently reported for other monoclonal antibodies, e.g. rituximab and efalizumab, and the latter was, therefore, withdrawn from the market [34].

We found a number of PML cases related to drugs classified as "others", such as fluorouracil, levamisole and calcium folinate (mentioned in literature) and vincristine and doxorubicin (from the two ADR databases). Levamisole, alone or in combination with 5-fluoruacil, can induce multiple inflammatory leukoencephalopathy with a subacute progressive decline [35], as has been well known for a long time. On the basis of this study all of the other drugs cannot be considered directly related to PML because they were often part of multiple schedule therapies.

Finally, although for serious life-threatening diseases (e.g. leukaemia, lymphoma) the balance of PML risk and treatment benefit seems acceptable, in chronic diseaseseven those that are severe and highly disabling such as autoimmune disorders - this risk/benefit profile becomes less favourable. Most authoritative guidelines on multiple sclerosis treatment, for instance, reflect this balance, limiting natalizumab to patients with severe relapsing disease [36]. In Italy, a few monoclonal antibodies, including natalizumab, are undergoing intensive ADR monitoring and ad hoc prescription registries have been formed [24, 37, 38] (see also: http://monitoraggio-farmaci. agenziafarmaco.it/).

Hence, a careful surveillance is strongly required for all new drugs, especially those targeted to autoimmune disorders (e.g. ustekinumab recently approved for the treatment of psoriasis).

\section{Conclusion}

Drug-induced PML represents one of the main current topics in pharmacovigilance, due to the severity of the disease and the lack of knowledge on its pathophysiology and course. The actual drug-induced PML incidence is still unknown, as is the contribution of underlying diseases.

To our knowledge, this is the first study providing a comprehensive picture of drug-induced PML cases, apart from a prepublished online case series on rituximab. The main PML cases analysed by us occurred in immunodepressive patients, affected primarily by HIV and immunosuppressive disorders. Since immunosuppression is thought to be a common predisposing factor for this ADR, in these 
circumstances PML-drug causality assessment is certainly biased. Nevertheless, a number of our cases also occurred in patients treated with monoclonal antibodies for autoimmune disorders, conditions that until now were only poorly associated with PML. In our data, monoclonal antibodies were often recognized as being the only drug associated with PML, and therefore the relationship between drug and adverse reaction gains more strength.

Based on our results, careful monitoring of patients treated with any biological drugs should be recommended to detect early signs and symptoms of PML. Urgently, at least rituximab and alemtuzumab should be included in close monitoring programmes.

Acknowledgements The authors are indebted to the national centres who contributed data. The opinions and conclusions, however, are not necessarily those of the various centres nor of the WHO.

Conflict of interest None of the authors have any potential conflict of interest with commercial parties.

Funding This study was funded with institutional funds from the Emilia-Romagna Region and from the University of Bologna (RFO).

\section{References}

1. Koralnik IJ (2004) New insights into progressive multifocal leukoencephalopathy. Curr Opin Neurol 17:365-370

2. Koralnik IJ (2006) Progressive multifocal leukoencephalopathy revisited: has the disease outgrown its name? Ann Neurol 60:162-173

3. Langer-Gould A, Atlas SW, Green AJ, Bollen AW, Pelletier D (2005) Progressive multifocal leukoencephalopathy in a patient treated with natalizumab. N Engl J Med 353:375-381

4. Kleinschmidt-DeMasters BK, Tyler KL (2005) Progressive multifocal leukoencephalopathy complicating treatment with natalizumab and interferon beta-1a for multiple sclerosis. N Engl J Med 353:369-374

5. Van Assche G, Van Ranst M, Sciot R, Dubois B, Vermeire S, Noman M, Verbeeck J, Geboes K, Robberecht W, Rutgeerts P (2005) Progressive multifocal leukoencephalopathy after natalizumab therapy for Crohn's disease. N Engl J Med 353:362-368

6. Yousry TA, Major EO, Ryschkewitsch C, Fahle G, Fischer S, Hou J, Curfman B, Miszkiel K, Mueller-Lenke N, Sanchez E, Barkhof F, Radue EW, Jager HR, Clifford DB (2006) Evaluation of patients treated with natalizumab for progressive multifocal leukoencephalopathy. N Engl J Med 354:924-933

7. Polman CH, O'Connor PW, Havrdova E, Hutchinson M, Kappos L, Miller DH, Phillips JT, Lublin FD, Giovannoni G, Wajgt A, Toal M, Lynn F, Panzara MA, Sandrock AW (2006) A randomized, placebo-controlled trial of natalizumab for relapsing multiple sclerosis. N Engl J Med 354:899-910

8. Berger JR (2007) Progressive multifocal leukoencephalopathy. Curr Neurol Neurosci Rep 7:461-469

9. U.S. Food and Drug Administration (FDA) (2009) FDA-AERS Adverse Event Reporting System. http://www.fda.gov/cder/aers/ default.htm. Accessed 23 Feb 2009

10. Northrup Grumman (2009) The Medical Dictionary for Regulatory Activities (MedDRA). Available via http://www.meddramsso. com/MSSOWeb/index.htm. Accessed 23 Feb 2009
11. World Health Organization (WHO) (2009) WHO-VigiBase.Uppsala Monitoring Centre. http://www.umc-products.com/DynPage.aspx? id $=4910 \& m n=1107$. Accessed 23 Feb 2009

12. World Health Organization (WHO) (2009) WHO Collaborating Centre for Drug Statistics Methodology. http://www.whocc.no/ atcddd/. Accessed 23 Feb 2009

13. Hammond IW, Gibbs TG, Seifert HA, Rich DS (2007) Database size and power to detect safety signals in pharmacovigilance. Expert Opin Drug Saf 6:713-721

14. Furberg CD, Levin AA, Gross PA, Shapiro RS, Strom BL (2006) The FDA and drug safety: a proposal for sweeping changes. Arch Intern Med 166:1938-1942

15. Pariente A, Gregoire F, Fourrier-Reglat A, Haramburu F, Moore N (2007) Impact of safety alerts on measures of disproportionality in spontaneous reporting databases: the notoriety bias. Drug Saf 30:891-898

16. Motola D, Vargiu A, Leone R, Conforti A, Moretti U, Vaccheri A, Velo G, Montanaro N (2008) Influence of regulatory measures on the rate of spontaneous adverse drug reaction reporting in Italy. Drug Saf 31:609-616

17. Hartnell NR, Wilson JP (2004) Replication of the Weber effect using postmarketing adverse event reports voluntarily submitted to the United States Food and Drug Administration. Pharmacotherapy 24:743-749

18. Hauben M, Reich L, DeMicco J, Kim K (2007) 'Extreme duplication' in the US FDA Adverse Events Reporting System database. Drug Saf 30:551-554

19. Falco V, Olmo M, del Saz SV, Guelar A, Santos JR, Gutierrez M, Colomer D, Deig E, Mateo G, Montero M, Pedrol E, Podzamczer D, Domingo P, Llibre JM (2008) Influence of HAART on the clinical course of HIV-1-infected patients with progressive multifocal leukoencephalopathy: results of an observational multicenter study. J Acquir Immune Defic Syndr 49:26-31

20. Aksamit AJ (2006) Review of progressive multifocal leukoencephalopathy and natalizumab. Neurologist 12:293-298

21. Boren EJ, Cheema GS, Naguwa SM, Ansari AA, Gershwin ME (2008) The emergence of progressive multifocal leukoencephalopathy (PML) in rheumatic diseases. J Autoimmun 30:90-98

22. U.S. Food and Drug Administration (FDA) (2006) Tysabri - FDA approval letter. http://www.fda.gov/cder/foi/appletter/2006/ 125104s015LTR.pdf. Accessed 23 Feb 2009

23. U.S. Food and Drug Administration (FDA) (2006) Tysabri - risk minimization action plan. http://www.fda.gov/cder/foi/appletter/ 2006/125104s015LTR.pdf. Accessed 23 Feb 2009

24. Mancardi GL, Amato MP, D'Alessandro R, Drago F, Milanese C, Popoli P, Provinciali L, Rossi P, Savettieri G, Tedeschi G, Tola MR, Vanacore N, Covezzoli A, De Rosa M, Piccinni C, Montanaro N, Periotto L, Addis A, Martini N (2008) Natalizumab: a country-based surveillance program. Neurol Sci 29(Suppl 2):S235-S237

25. Giezen TJ, Mantel-Teeuwisse AK, Straus SM, Schellekens H, Leufkens HG, Egberts AC (2008) Safety-related regulatory actions for biologicals approved in the United States and the European Union. JAMA 300:1887-1896

26. Carson KR, Focosi D, Major EO, Petrini M, Richey EA, West DP, Bennett CL (2009) Monoclonal antibody-associated progressive multifocal leucoencephalopathy in patients treated with rituximab, natalizumab, and efalizumab: a review from the Research on Adverse Drug Events and Reports (RADAR) project. Lancet Oncol 10:816-824

27. Uetrecht J (2009) Immune-mediated adverse drug reactions. Chem Res Toxicol 22:24-34

28. Hamilton CD (2004) Infectious complications of treatment with biologic agents. Curr Opin Rheumatol 16:393-398

29. Bongartz T, Sutton AJ, Sweeting MJ, Buchan I, Matteson EL, Montori V (2006) Anti-TNF antibody therapy in rheumatoid 
arthritis and the risk of serious infections and malignancies: systematic review and meta-analysis of rare harmful effects in randomized controlled trials. JAMA 295:2275-2285

30. Strangfeld A, Listing J, Herzer P, Liebhaber A, Rockwitz K, Richter C, Zink A (2009) Risk of herpes zoster in patients with rheumatoid arthritis treated with anti-TNF-alpha agents. JAMA 301:737-744

31. Rudick RA, Stuart WH, Calabresi PA, Confavreux C, Galetta SL, Radue EW, Lublin FD, Weinstock-Guttman B, Wynn DR, Lynn F, Panzara MA, Sandrock AW (2006) Natalizumab plus interferon beta-1a for relapsing multiple sclerosis. N Engl J Med 354: 911-923

32. Sandborn WJ, Colombel JF, Enns R, Feagan BG, Hanauer SB, Lawrance IC, Panaccione R, Sanders M, Schreiber S, Targan S, van Deventer S, Goldblum R, Despain D, Hogge GS, Rutgeerts P (2005) Natalizumab induction and maintenance therapy for Crohn's disease. N Engl J Med 353:1912-1925

33. Hartung HP (2009) New cases of progressive multifocal leukoencephalopathy after treatment with natalizumab. Lancet Neurol $8: 28-31$
34. European Agency for the Evaluation of Medicinal Products (EMEA) (2009) European Medicines Agency recommends suspension of the marketing authorisation ofRaptiva (efalizumab). EMEA/CHMP/ 20857/2009. http://www.emea.europa.eu/humandocs/PDFs/EPAR/ raptiva/2085709en.pdf. Accessed 1 Apr 2009

35. Wu VC, Huang JW, Lien HC, Hsieh ST, Liu HM, Yang CC, Lin YH, Hwang JJ, Wu KD (2006) Levamisole-induced multifocal inflammatory leukoencephalopathy: clinical characteristics, outcome, and impact of treatment in 31 patients. Medicine (Baltimore) $85: 203-213$

36. National Institute for Health and Clinical Excellence (NICE) (2007) Natalizumab for the treatment of adults with highly active relapsing- remitting multiple sclerosis. www.nice.org.uk

37. Naldi L, Addis A, Chimenti S, Giannetti A, Picardo M, Tomino C, Maccarone M, Chatenoud L, Bertuccio P, Maggese E, Cuscito R (2008) Impact of body mass index and obesity on clinical response to systemic treatment for psoriasis. Evidence from the Psocare project. Dermatology 217:365-373

38. Nijsten T, Wakkee M (2008) Psocare: Italy shows the way in postmarketing studies. Dermatology 217:362-364 